\title{
The Applications of Game Theory and Its Contributions to Economics
}

\author{
Tailo Yeung \\ Institute of Finance and Banking, Chinese Academy of Social Sciences, Beijing 100028, \\ China. \\ arlis_yeung@yahoo.com
}

\begin{abstract}
In just a few decade development processes, game theory, with its innovative ideas, strong economic analysis tools, and complete and rigorous system, has brought new vigor to the economics, and managed to reinterpret some traditional economic theory more reasonably, and let economists have the ability to explore some new areas. This paper summarizes and analyses the application of game theory in the socio-economic analysis and its contribution to economics. The assortment and study of economic game theory not only is beneficial to further understand the essence and the process of the development of this field, but also provide ideas and reference for the future development of it.
\end{abstract}

Keywords: Game theory; socio-economic analysis; information economics; economic rationalism.

\section{Introduction}

Game theory is a subject that studies the conflict and cooperation between rational individuals. Von Neumann and Morgenstern's famous "game theory and economic behavior", which was published in 1944, is marking that the creation of Game theory. But after the Nash's two foundational articles in the field of non-cooperative game published in the early 1950s, Game theory was beginning to develop rapidly [1-3].

Game theory has a profound impact on the way of thinking of economists. It is increasingly recognized that most of the economic problems can be analyzed as a game process. Game theory can help economists to understand and predict what has happened and what is going to happen in the economic environment. Many scholars tried to use game theory to study the micro- and macroeconomic theoretical problem, and even wanted to reconstruct the theoretical framework of economics through this approach $[4,5]$.

This paper summarizes and discusses the game theory application in the socio-economic analysis and its contribution to economic, and to sum up, it mainly reflected in three aspects: First is provided new methods for the study of economics and the socio-economic analysis, the second is promoted the rise of information economics, and the third is led to the revolution of economic rationalism.

\section{Game Theory in the Socio-economic Analysis}

The traditional application field of game theory is the study of industrial organization, market structure, the analysis of voting and public goods supply. Game theory, such as the iterated prisoner's dilemma, staggered price bargaining model, time selection game and preemption game, was applied to analysis of industrial organization theory. Hassan's Bias Nash equilibrium solution, as the cornerstone of many games reasoning analysis, was applied to the problem of "mechanism design", including the nonlinear price discrimination, the best auction, the display of preferences for public goods and the failure of the contract in the case of incomplete information and so on. A series of the concept of solution applied to the analysis of predatory behavior and the employment market signals - the fully Bayesian equilibrium solution, Kreps and Wilson sequence equilibrium, Selten trembling hand perfect equilibrium solution, and embodies the thought of expanded perfect point of neutron game in incomplete information game [6-8]. In recent years, game theory has been applied to the analysis of different auction behaviors, the relationship between clients and agents, and the incentive mechanism, as well as the field of public finance.

Constructing a game model for the economy problem is carried out in a very natural way: behavioral agent acts as consumers, and manufacturer acts as the player; consumer consumption, the 
manufacturer's production, prices etc. acts as a strategic variable; utility or profit as a payment. The relationship between payment and strategic variable is described by the utility function and profit function. What's it different from traditional analysis is that the payment function is a function of all the players' strategic variables. The intertwined interests relationship may be derived from consumer preference structure or production function itself - someone may feel benefit losing when he sees other people consuming more because of envy, and manufacturers will change their production function when their competitors take some actions (for example, competitors sell a new technology which has just been developed). But more often, the externalities of behavior is derived from the imperfect competition between the players - in a market that has a small number of buyers and sellers, other people's consumption will directly affect the price level, and then will affect your consume level and other manufacturers' sales, and also affect the sales and prices of a vendor's products. If in a game the player's payments is only a function of their own and has nothing to do with the rest of the players, and meanwhile the information is complete, it means that is the neoclassical microeconomic environment: consumers according to their preferences and the given price to maximize their effectiveness in revenue constraints; manufacturers according to exogenous price levels to choose the profit-maximizing output. Therefore, new classical environmental economic competition is a kind of special game, and the number of player is so many that the effect of any player's behavior is negligibly small. Moreover, the information is complete. Naturally, game theorists will be interested in such a special game. The reason for the wide success of game theory lies in that it provides a set of strict and complete analytical methods for the interaction between various information structures associated individuals. Understandably, game theory rewrite microeconomics through relaxing two conditions of the neo-classical economic -complete competition and complete information.

\section{The rise of Information Economics}

Another important contribution of game theory to economics is that it has greatly promoted the development of information economics. There's no doubt about that since the 1970s, the rapid rise of the information economics has radically overthrown the mainstream status of the new classical micro economics [9].

The study of information economics is the optimal decision making of the individual behavior in asymmetric information. In asymmetric information, the party that has private information is called the agent, and the other that does not have private information is called principal. Even until the mid1960 s, economists believed that such a problem cannot be analyzed. Because if the agent is acting according to private information at their disposal, while the principal does not know this information, from the client perspective, the identity of the other simply cannot be confirmed. If there are $\mathrm{N}$ possible agent, the agent know which one they belong to, but the client does not know, this situation is similar to that principal deal with $\mathrm{N}$ different agents, but he could not confirm that which one he deal with. In late 1960s, game theory scholar J.C. Harsanyi broke through this dilemma. Harsanyi proposed technology to deal with incomplete information game, expanded the Nash equilibrium concept in complete information game to incomplete information game, and defined the Bayes-Nash equilibrium. On the basis of this, incomplete information game (especially non-symmetric information game theory) got a great development, and therefore, information economics also fast to develop. In the asymmetric information environment, the participation constraints and the incentive compatibility constraint are the preconditions to guarantee the principal-agent relationship. All kinds of problems in information economics can be generally expressed as the problem of the maximization of the principal's utility (profit) under the participation constraint and incentive compatibility constraints, and the Bias Nash equilibrium is the most basic solution. The method of Asymmetric information game theory analysis completely changed the face of microeconomics. 


\section{Game Theory Revolution of Economic Rationalism}

Economics has a long history for the understanding and application of reason. From the beginning of classical economics, the rational hypothesis of human behavior has been taken as an important prerequisite for the study of economics. However, in microeconomics, for a long time the rationalism only plays a role in the narrow world of Walrasian general equilibrium system. Game theory introduced into the economic analysis not only let the economists revisit the "rational man" - the basic assumptions of the original meaning, but also pushed the status of individual rationality axiom in economics to the extreme. As a branch of economics, game theory's main object of study is an interactive behavior of economic agents, and its logic starting point of the analysis of behavioral agent is similar to mainstream economics method, and game theory believed that the behavior of behavioral agent is in line with the principle of rationality. Developed on the basis of rational hypothesis, noncooperative game theory has a beautiful, rigorous mathematical reasoning and mathematical models, and has been widely and successfully applied in political science, sociology, history, philosophy, ethics and other social sciences. The mid-1990s is the most glorious period of game theory. Economists have found that almost all economic problems can be understood as problem of interaction between rational actors.

Although man's rationality is limited, evolutionary game theory makes it easy for us to analyze and solve the problem of bounded rationality. Bounded rational players often do not find the optimal strategy at first, but they will learn the game in the course of the game, and through trial and error to find a better strategy. This means that the equilibrium is a result of constant adjustment and improvement, not a one-time option, and even once reached equilibrium may deviate again. Therefore, the real equilibrium in bounded rational game must be achieved by players' continuously imitation and learning, and must have the ability of resistance to deviate from interfering, that's the evolutionary equilibrium state, which is composed of the evolutionary stable strategy. The meaning of analyze game theory under the condition of limited rationality is not to predict the one-time game results or short-term economic equilibrium, but to analyze the long-term stable trend of non-fixed object economic relations between people in a relatively stable environment. Moreover, it can also be used as tools to choose or to prove the conclusion of the game theory analysis. Obviously, the idea and method of "evolutionary equilibrium" put forward by the game theory makes the requirements of the economic analysis of human rational conditions greatly relaxed.

\section{Conclusion}

Game theory is the theory of conflict and cooperation between rational decision makers, and can provide theoretical basis and guidance on the actual decision. Game theory has been widely used in economics, political science, management science, international relations, interpersonal relationship science, diplomacy, criminology etc. And its ultimate pursuing result is player's equilibrium of maximizing the benefits. Especially, game theory as an analytical tool and an important branch of economics, have dramatically changed the face of economics: broaden the field of economics; changed the research of isolated individual decision and the balance behavior under conditions of perfect competition in traditional economics; focused on the analysis of behavioral characteristics of the multi-stakeholder and the interaction between them, and made economic analysis to better reflect the essential characteristics of the human factor. This article summarizes and discusses the application of game theory in the socio-economic analysis economy and its contribution to the economics - provided a new method for major economics research and the socio-economic analysis, promoted the development of information economics, resulted in the economic rationalism revolution. The arrangement and research of economic game theory not only beneficial to further understand the essence and the process of development of this field, but also provide ideas and reference for the future development of game theory. 


\section{References}

[1] Dianchun Jiang, How's game theory rewrite the micro economics, Economist, vol. 6, pp. 86-95, 1997.

[2] M. J. Osborne and A. Rubinstein, A course in game theory: MIT press, 1994.

[3] J. Von Neumann and O. Morgenstern, Theory of games and economic behavior: Princeton university press, 2007.

[4] R. Gibbons, A primer in game theory: Harvester Wheatsheaf, 1992.

[5] C. Camerer, Behavioral game theory: Experiments in strategic interaction: Princeton University Press, 2003.

[6] Kreps, D. M., \& Wilson, R. (1982). Sequential equilibria. Econometrica: Journal of the Econometric Society, 863-894.

[7] Myerson, R. B. (1985). Bayesian equilibrium and incentive-compatibility: An introduction. Social goals and social organization: Essays in memory of Elisha Pazner, 229-260.

[8] Selten, R. (1983). Evolutionary stability in extensive two-person games.Mathematical Social Sciences, 5(3), 269-363.

[9] Lamberton, D. M. (Ed.). (1971). Economics of information and knowledge: Selected Readings. [Harmondsworth, Eng.]: Penguin Books. 